\title{
Comparison of Surgical Parameters Using Different Lens Fragmentation Patterns in Eyes Undergoing Laser Assisted Cataract Surgery
}

Harvey S. Uy MD1,2, Pik Sha Chan, MD1, Raquel Gil-Cazorla3, Sunil Shah, MD4

1) Peregrine Eye and Laser Institute, Makati City, Philippines

2) University of the Philippines, Manila, Philippines

3) Ophthalmic Research Group, Aston University, Birmingham, United Kingdom

4) Birmingham \& Midland Eye Centre, Birmingham, United Kingdom

Disclosures:

Drs. Harvey Uy and Sunil Shah have received research grants from LENSAR, Inc Dr. Pik Sha Chan has no financial interests in this paper

Corresponding author:

Harvey S. Uy, MD

Peregrine Eye and Laser Institute

50 Jupiter Street

Makati City, Philippines 1209

Tel: +6328900115

Fax: +6325118504

Email: harveyuy@yahoo.com 


\section{ABSTRACT}

Purpose: To compare surgical parameters among eyes undergoing laser-assisted cataract surgery (LACS) using different lens fragmentation patterns (LFP).

Methods: Prospective, randomized, unmasked clinical trial. One-hundred eyes underwent LACS and were randomly assigned to 1 of 3 LFP treatment groups: 1 ) laser capsulotomy only; no lens fragmentation (NLF) ( $n=34) ; 2)$ three-plane chop (TPC) ( $n=33)$; and, 3) pie-cut pattern (PCP) fragmentation ( $n=33$ ). Prechop phacoemulsification (PHACO) was performed on all eyes using the same femtosecond (FS) laser and active fluidics PHACO machine. Main outcome measures: FS laser dock time (seconds), PHACO time (seconds), PHACO power (\%), cumulative dissipated energy (CDE) (\%-seconds), irrigating fluid volume and operative time.

Results: The 3 treatment groups were comparable in terms of patient age $(P=0.164)$ and nuclear density $(P=0.669)$. FS dock time was higher in the PCP group $(184.18 \pm 25.86)$ compared to the TPC $(145.09 \pm 14.15)$ group $(P<0.001)$. PHACO time was significantly shorter in the PCP $(23.19 \pm 17.20$ seconds) compared to TPC $(35.27 \pm 17.70)$ and NLF $(46.15 \pm 23.72)$ groups $(P<0.001)$. PHACO power was lower in the PCP $(11.81 \pm 3.71)$ compared to the NLF $(14.41 \pm 1.88)$ and TPC $(14.04 \pm 2.46)$ groups $(P<0.001)$. CDE was lower in the PCP $(2.85 \pm 2.32)$ compared to NLF $(6.55 \pm 3.32)$ and TPC $(6.55 \pm 5.45)$ groups $(P<0.001)$. Fluid volumes and operative times were similar.

Conclusion: LFP can influence PHACO surgical parameters. Extensive fragmentation patterns such as PCP appear to lower PHACO time, power and CDE and may potentially reduce the risk of PHACO related complications.

Keywords: laser-assisted cataract surgery; LACS; phacoemulsification; lens fragmentation

\section{INTRODUCTION}

Phacoemulsification (PHACO) is currently the standard of care for cataract surgery in the developed world. Since its introduction in the late 1960 s by Kelman [1], PHACO technology has evolved by incorporating improvements in ultrasonic energy delivery [2-4], fluidics [5,6], and instrumentation [7]. Despite these advances, PHACO may still cause vision threatening complications such as corneal endothelial cell (EC) loss, corneal edema, posterior capsular rupture, vitreous loss, and postoperative infection. EC loss may be higher in PHACO compared to extra-capsular cataract extraction (ECCE) when treating higher grade cataracts [8]. The reported range of EC loss varies from $14.5 \%$ to $26 \%$ in the early days of PHACO $[9,10]$, to as little as $5 \%$ with modern PHACO energy modulation software and advanced instrumentation [11].

EC loss is believed to result from heat generated by ultrasonic tips [12], anterior chamber fluid turbulence [13], the impact of cavitation bubbles on the endothelium [14], and reactive oxygen species (free radicals) generated during ultrasonic energy delivery [15-17]. In an attempt to reduce the harmful sequelae of PHACO, the use of laser energy to break up the lens nucleus has been explored. Dodick initially described the use of Nd:YAG and erbium:YAG laser to fragment the lens [18-21]. However, this photolysis technique was not always successful and required conversion to standard ultrasound PHACO in up to $46 \%$ of cases $[22,23]$.

Laser-assisted cataract surgery (LACS) uses ultrashort pulse lasers to precisely photodisrupt the crystalline lens [24-26]. Several authors have reported reduction of PHACO time and energy as well as reduction of EC loss among animal and human eyes undergoing laser lens fragmentation (LLF) [27- 
32]. These reports consist of a large case series comparing surgical parameters in eyes that underwent conventional PHACO versus LACS [30-32]. There are few randomized clinical trials (RCT) examining the effectiveness of different LACS treatment parameters on PHACO surgical outcomes. Conrad-Hengerer et al reported that using smaller grid softening patterns significantly decreased the amount of effective PHACO time used for cataract surgery [32]. We wanted to compare the effects of using a simple laser chop pattern versus a more extensive chop and lens segmentation pattern on surgical parameters among eyes undergoing (LACS).

\section{PATIENTS AND METHODS}

This prospective, randomized, unmasked, clinical trial included 100 consecutive eyes of 100 adults that underwent PHACO surgery at an ambulatory surgical center (Peregrine Eye and Laser Institute, Makati, Philippines) from January 1, 2016 to June 30, 2016. Eyes with opacification within $7 \mathrm{~mm}$ of the central cornea, pupillary dilation of less than $6 \mathrm{~mm}$ in diameter, zonular weakness, and white cataracts were excluded. The study protocol and informed consent forms were reviewed and approved by an independent review board (Peregrine Eye and Laser Institute - Institutional Review Board, Makati City, Philippines). Potential patients were given an option to enter the study and undergo FS laser treatment with the FS laser cost assumed by Peregrine Eye and Laser Institute. The cost of PHACO surgery and intraocular lens was covered by the patient or their health insurance provider. All patients provided a signed informed consent prior to the start of study procedures.

Diagnostic Procedures

Patient age was recorded. For objective assessment of cataract density, Scheimpflug images were obtained (Pentacam HR, Oculus Optikgerate GmbH, Wetzlar, Germany) under pupil dilatation with $0.5 \%$ phenylephrine/tropicamide drops (Sanmyd, Santen, Osaka, Japan). All images were obtained in a consistent environment using the same device, after equipment calibration. The operator visualized a real-time image of the patient's eye on a computer screen and manually focused and aligned the image. The automatic release mode was employed to reduce operator-dependent variables. In this mode, the instrument automatically determined the correct focus and alignment with the corneal apex and then obtained a scan.

The Pentacam Scheimpflug lens densitometry method analyses blue light-scattering intensity of the different lens layers to grade nuclear density objectively. On the three-dimensional plot of the anterior segment with each section running through the corneal vertex, the required lens density was taken as the mean value on the image at 45 degrees in both eyes, using the traditional lens density assessment function available in the software Pentacam Nuclear Staging (PNS) software. In cases in which the image could not be obtained at 45 degrees, the image with better lens visualization was selected. The numerical nuclear density for each was recorded.

Randomization Procedure:

On the day of the surgery, each eye was assigned to receive 1 of 3 treatments based on the results of an online true random number generator (www.random.org) which generates random numbers based on atmospheric noise. Just prior to LACS surgery, the true random number generator assigned " 1 ", " 2 ", or " 3 " to each eye. The eyes then received the corresponding treatment as follows: (1) laser capsulotomy only, no lens fragmentation (NLF); (2) capsulotomy with 3-plane chop (TPC); or, (3) capsulotomy with pie-cut pattern fragmentation (PCP). Surgical microscope views of each group are shown in Figure 1. 
Femtosecond laser procedure

For eyes assigned to undergo LACS, the study eye was docked to the FS laser (Lensar, Orlando, FL) via a suction ring and a non-applanating, index-matching patient interface device. The anterior segment was imaged using the FS laser's built-in high resolution, variable scan rate, augmented reality imaging system. The FS laser was then used to create a $5.25 \mathrm{~mm}$, optical axis-centered (centered on the capsular bag), anterior capsulotomy followed by LLF according to the assigned treatment group (TPC or PCP), and finally, a 3-plane, $2.4 \mathrm{~mm}$ wide, temporal, clear corneal incision. Dock time was measured in seconds, from the onset of suction to the removal of the suction ring. The laser energy settings are provided in Table 1.

Phacoemulsification Procedure

All surgeries were completed by a single surgeon (HSU) using the same PHACO machine and PHACO tip (Centurion Vision System, Alcon Surgical, Ft. Worth, TX). After aseptic prepping and draping, the surgeon used a $1.2 \mathrm{~mm}$ keratome to create a side port through which unpreserved lidocaine $2 \%$ and epinephrine and the ophthalmic viscoelastic device (OVD) (Discovisc, Alcon Surgical, Ft Worth, TX) were sequentially injected into the anterior chamber. A Sinskey hook was used to open the $2.4 \mathrm{~mm}$, 3-plane, laser-created, clear corneal incisions. Capsular forceps were used to remove the capsular button. Careful hydrodissection and hydrodelineation were performed. Coaxial PHACO was then performed using a standard 3-plane, prechop technique. An acrylic IOL was implanted into the capsular bag. At the end of surgery, PHACO time (seconds), PHACO energy (\%), CDE (\%-seconds), and utilized irrigation fluid (milliliters) were recorded from the PHACO machine screen.

The main outcome measures were: age, nuclear density grading, dock time, PHACO time, PHACO power, cumulative dissipative energy (CDE), irrigating fluid volume, $\mathrm{PHACO}$ operative time (minutes), and adverse events. In an effort to avoid confounding the analysis of operative times, we did not create laser side port incisions because of the large variability in ease and duration of opening side port incisions.

\section{Sample Size Calculation}

Based on a pilot study, we determined that the mean $C D E$, using a Centurion machine to perform conventional PHACO, was $8.6 \pm 3.45 \%$-seconds. To detect a $33.3 \%$ decrease in CDE at a $5 \%$ level of significance, we used the formula for a sample size of three means (sample size $=22 \mathrm{~s} 2 / \mathrm{d} 2$ ) to determine the per group sample size. Applying the results from our pilot study, the study sample size was calculated to be: $22(3.45) 2 /(2.86) 2+1=33.0$ per group.

Statistical Analysis

Data obtained was carefully recorded and analyzed using SPSS version 17.0. Statistical significance was set at $95 \%$ confidence intervals, i.e., at a $p$-value of $<0.05$. For categorical variables such as nuclear sclerosis grading, the Chi-square test was used. For comparison of means, one-way analysis of variance was used. 


\section{RESULTS}

The three treatment groups were comparable in terms of patient age $(P=0.164)$ and distribution of cataracts according to nuclear density grading $(P=0.669)$. The FS dock time was higher in the PCP group (184.18 \pm 25.86$)$ compared to the TPC $(145.09 \pm 14.15$ seconds) group $(P<0.001)$.

PHACO time was significantly shorter in the PCP $(23.19 \pm 17.20$ seconds) compared to TPC ( $35.27 \pm$ $17.70)$ and NLF $(46.15 \pm 23.72)$ groups $(P<0.001)$. PHACO power was significantly lower in the PCP $(11.81 \pm 3.71 \%)$ compared to the NLF $(14.41 \pm 1.88)$ and TPC $(14.04 \% \pm 2.46)$ groups $(P<0.001)$. And, CDE was significantly lower in the PCP $(2.85 \pm 2.32 \%$-seconds) compared to NLF $(6.55 \pm 3.32)$ and TPC $(6.55 \pm 5.45)$ groups $(P<0.001)$.

Fluid volumes $(P=0.887)$ and operative times $(P=0.619)$ were similar in all 3 groups. No adverse events were observed among all groups. (Table 1 )

\section{DISCUSSION}

Minimizing the amount of ultrasonic energy used during cataract surgery reduces anterior chamber turbulence, cavitation bubbles, temperature rise [12], free radical generation [15-17], endothelial cell damage, anterior chamber inflammation, and ultimately, promotes surgical recovery. In LACS, ultra-short pulse lasers fragment the lens prior to cataract surgery, softening the cataract and reducing the energy requirement for nuclear disassembly. However, only a few controlled studies have reported the efficacy of FS laser lens fragmentation for reducing the PHACO energy needed for nuclear disassembly [32].

Modern PHACO machines use sophisticated control software that also measure PHACO power and PHACO time in order to determine absolute energy delivery. In this study, the CDE was calculated by the system software and accounted for utilized torsional and longitudinal PHACO energy, energy modulation, and the percentage of maximal PHACO energy. Together, this information provides the best measure of total energy delivered during the surgery. To determine the effect of laser lens fragmentation, comparison of the PHACO energy used for laser-treated eyes with an untreated control (NLF) group using the same FS laser and PHACO equipment is perhaps the most valid comparison. Because of randomized treatment assignment, a strength of this study is that the 3 treatment groups were comparable in terms of nuclear density.

FS lasers are capable of cutting tissues and may complement PHACO systems to improve the energy efficiency of nuclear disassembly. This study has clearly demonstrated that LLF significantly reduces the amount of ultrasound energy needed for nuclear disassembly. Furthermore, the results demonstrate that the amount of ultrasonic energy reduction is influenced by the type or extent of laser lens fragmentation pattern. The more extensive the fragmentation pattern applied, the less ultrasonic energy is needed for nuclear disassembly. This energy reduction is achieved without increasing irrigation fluid volumes or operative times.

Regarding safety, while substitution with laser energy may reduce ocular exposure to the detrimental effects of PHACO energy, it is important to ensure laser application does not introduce other adverse effects. FS lasers have been used in refractive surgery for many years, and there is no evidence that laser treatment within the cornea has significant effects on endothelium morphology $[33,34]$. Concern may extend to the effects on the retina since a proportion of the incident energy may pass beyond the structures being treated. The damage may be due to temperature rise, phototoxic effects, or both $[35,36]$. Experimentation has determined thresholds for retinal damage 
and calculations of the maximum exposure of retinal tissues to laser radiation passing from the anterior eye during LAC and LLF have been made to ensure that thresholds are not breached [37-39].

In a recently published, non-randomized comparative study, Al-Mohtaseb et al reported that compared to conventional PHACO, LACS treatment significantly decreased the amount of CDE by $33 \%$, and endothelial cell loss by $22.5 \%$ [40]. In a similar study, Yesilirmak et al examined the effectiveness of LACS treatment for reducing CDE when different PHACO machines were used. They reported a reduction of CDE by 33\% among eyes undergoing LACS and PHACO when an activefluidics PHACO machine was used compared to a reduction of CDE by $39 \%$ when a gravity-fluidics PHACO machine was used [41]. In this study, we observed a reduction of CDE by $11 \%$ using a TPC pattern and by $56 \%$ when using the more extensive PCP.

There is currently no standard lens fragmentation pattern that all surgeons utilize during LACS treatment. Some surgeons do not use lens fragmentation but only restrict laser application to capsulotomy; some only use the laser to create planar chops to section the nucleus into a few large fragments. Others utilize full fragmentation patterns that divide the nucleus into numerous small fragments. Still, others use a combination of treatment patterns. Theoretically, more extensive fragmentation, (eg. PCP pattern) would lead to the greatest reduction in required energy for nuclear disassembly. Therefore, studies to determine the efficiency of LLF for nuclear disassembly should ideally take into consideration the type of LLF pattern used as well as nuclear density grading, which has been demonstrated to influence the amount of PHACO energy utilization $[32,42]$. Compared to the TPC pattern, PCP application requires a small increase in FS dock time due to additional time needed to complete the more extensive laser treatment pattern. While this, approximately 20 second, additional laser treatment time does not significantly increase patient discomfort nor total procedural time, the extra period does provide a small window for inadvertent undocking among restless patients. It is likely that future femtosecond laser software of hardware upgrades will result in faster data processing and shorten the additional time it takes to complete the PCP pattern and limit the risk of intraoperative laser undocking.

The limitations of the present study include small sample size and having a single, expert surgeon perform all the surgeries with a single PHACO technique and PHACO machine. These results may not be generalizable to other surgeons, FS laser machines, nor PHACO techniques or machines. Due to the small numbers of patients, we could not perform subgroup analysis per nuclear density grading. Future studies should include surgeons of different skill levels and the use of different PHACO techniques and FS laser machines. Furthermore, as cataracts are of different size and nuclear density, future research should be directed towards customizing LLF pattern to specific cataract types and densities. One shortcoming is that we lack long term endothelial cell count follow up.

The results from this study suggest that the type of lens fragmentation pattern used during LACS influences the amount of ultrasonic energy used during PHACO cataract surgery. Appropriate selection of an LLF pattern can improve surgical efficiency and potentially reduce the risks for surgical complications. These results can also guide manufacturers and surgeons in optimizing LACS technology by customizing treatment patterns to individual cataracts. 


\section{COMPLIANCE WITH ETHICAL STANDARDS}

Conflict of Interest: Drs. Harvey Uy and Sunil Shah have received research grants from LENSAR, Inc Dr. Raquel Gil-Cazorla was a former employee of LENSAR, Inc. The authors report no other conflict of interest.

Ethical Approval: All procedures performed in studies involving human participants were in accordance with the ethical standards of the institutional and/or national research committee and with the 1964 Helsinki declaration and its later amendments or comparable ethical standards.

Informed Consent: Informed consent was obtained from all individual participants included in the study.

\section{REFERENCES}

1. Kelman CD (1967) Phaco-emulsification and aspiration. A new technique of cataract removal. A preliminary report. Am J Ophthalmol; 64:23-35.

2. Fishkind W, Bakewell B, Donnenfeld ED, Rose AD, Watkins LA, Olson RJ (2006) Comparative clinical trial of ultrasound phacoemulsification with and without the WhiteStar system. J Cataract Refract Surg 32:45-49.

3. Vasavada AR, Raj SM, Patel U, Vasavada V, Vasavada V (2010) Comparison of torsional and microburst longitudinal phacoemulsification: a prospective, randomized, masked clinical trial. Ophthalmic Surg Lasers Imaging 41:109-114.

4. Zeng M, Liu X, Liu Y, Xia Y, Luo L, Yuan Z, Zeng Y, Liu Y (2008) Torsional ultrasound modality for hard nucleus phacoemulsification cataract extraction. Br J Ophthalmol 92:1092-1096.

5. Georgescu D, Kuo AF, Kinard KI, Olson RJ (2008) A fluidics comparison of Alcon Infiniti, Bausch \& Lomb Stellaris, and Advanced Medical Optics Signature phacoemulsification machines. Am J Ophthalmol 145:1014-1017.

6. Hoffman RS, Fine IH, Packer M (2005) New phacoemulsification technology. Curr Opin Ophthalmol 16:38-43.

7. Busic M, Kastelan S (2005) Pseudoexfoliation syndrome and cataract surgery by phacoemulsification. Coll Antropol 29 Suppl 1:163-166.

8. Bourne RR, Minassian DC, Dart JK, Rosen P, Kaushal S, Wingate N (2004) Effect of cataract surgery on the corneal endothelium: modern phacoemulsification compared with extracapsular cataract surgery. Ophthalmology 111:679-685.

9. Irvine AR, Kratz RP, O'Donnell JJ (1978) Endothelial damage with phacoemulsification and intraocular lens implantation. Arch Ophthalmol 96:1023-1026.

10. Ko YC, Liu CJ, Lau LI, Wu CW, Chou JC, Hsu WM (2008) Factors related to corneal endothelial damage after phacoemulsification in eyes with occludable angles. J Cataract Refract Surg 34:46-51.

11. Davison JA (2007) Comparison of ultrasonic energy expenditures and corneal endothelial cell density reductions during modulated and non-modulated phacoemulsification. Ophthalmic Surg Lasers Imaging 38:209-218.

12. Reepolmaha S, Limtrakarn W, Uthaisang-Tanechpongtamb W, Dechaumphai P (2010) Fluid temperature at the corneal endothelium during phacoemulsification: comparison of an ophthalmic viscosurgical device and balanced salt solution using the finite element method. Ophthalmic Res 43:173-178. 
13. Binder PS, Sternberg H, Wickman MG, Worthen DM (1976) Corneal endothelial damage associated with phacoemulsification. Am J Ophthalmol 82:48-54.

14. Kim EK, Cristol SM, Geroski DH, McCarey BE, Edelhauser HF (1997) Corneal endothelial damage by air bubbles during phacoemulsification. Arch Ophthalmol 115:81-88.

15. Geffen N, Topaz M, Kredy-Farhan L, Barequet IS, Farzam N, Assia El, Savion N (2008) Phacoemulsification-induced injury in corneal endothelial cells mediated by apoptosis: in vitro model. J Cataract Refract Surg 34:2146-2152.

16. Nemet AY, Assia El, Meyerstein D, Meyerstein N, Gedanken A, Topaz M (2007) Protective effect of free-radical scavengers on corneal endothelial damage in phacoemulsification. J Cataract Refract Surg 33:310-315.

17. Takahashi $\mathrm{H}$ (2005) Free radical development in phacoemulsification cataract surgery. J Nippon Med Sch 72:4-12.

18. Dodick JM, Christiansen J (1991) Experimental studies on the development and propagation of shock waves created by the interaction of short Nd:YAG laser pulses with a titanium target. Possible implications for Nd:YAG laser phacolysis of the cataractous human lens. J Cataract Refract Surg 17:794-797.

19. Dodick JM, Lally JM, Sperber LT (1993) Lasers in cataract surgery. Curr Opin Ophthalmol 4:107-109.

20. Kanellopoulos AJ, Dodick JM, Brauweiler P, Alzner E (1999) Dodick photolysis for cataract surgery: early experience with the Q-switched neodymium: YAG laser in 100 consecutive patients. Ophthalmology 106:2197-2202.

21. Kanellopoulos AJ (2001) Laser cataract surgery: A prospective clinical evaluation of 1000 consecutive laser cataract procedures using the Dodick photolysis Nd:YAG system. Ophthalmology 108:649-654.

22. Lin ZD, Feng B, Cheng B, Zou YP (2003) [The preliminary study of photolysis for cataract surgery]. Zhonghua Yan Ke Za Zhi 39:601-604.

23. Hoh H, Fischer E (2000) Pilot study on erbium laser phacoemulsification. Ophthalmology 107:1053-1061.

24. Mian SI, Shtein RM (2007) Femtosecond laser-assisted corneal surgery. Curr Opin Ophthalmol 18:295-299.

25. Toropygin SG, Krause M, Riemann I, Seitz B, Mestres P, Ruprecht KW, Konig K (2008) In vitro femtosecond laser-assisted nanosurgery of porcine posterior capsule. J Cataract Refract Surg 34:2128-2132.

26. Touboul D, Salin F, Mortemousque B, Courjaud A, Chabassier P, Mottay E, Leger F, Colin J (2005) [Tissular and mechanical effects observed with an experimental femtosecond laser microkeratome for corneal refractive surgery]. J Fr Ophtalmol 28:274-284.

27. Frey RW, Edwards K, Naranjo Tackman R, Villar Kuri J, Quezada N, Bunch T, Bott S (2010) Changes in CDE With Laser Lens Fragmentation Compared With Standard Phacoemulsification Cataract Surgery. Invest Ophthalmol Vis Sci 51:5418.

28. Nagy Z, Takacs A, Filkorn T, Sarayba M (2009) Initial clinical evaluation of an intraocular femtosecond laser in cataract surgery. J Refract Surg 25:1053-1060.

29. Takacs AI, Kovacs I, Mih_altz K, Filkorn T, Knorz MC, Nagy ZZ (2012) Central corneal volume and endothelial cell count following femtosecond laser-assisted refractive cataract surgery compared to conventional phacoemulsification. J Refract Surg 28:387-391.

30. Abell RG, Kerr NM, Vote BJ (2013) Femtosecond laser-assisted cataract surgery compared to conventional cataract surgery. Clin Experiment Ophthalmol 41(5):455-62. 
31. Reddy KP, Kandulla J, Auffarth GU (2013) Effectiveness and safety of femtosecond laserassisted lens fragmentation and anterior capsulotomy versus the manual technique in cataract surgery. J Cataract Refract Surg 39(9):1297-306.

32. Conrad-Hengerer I, Hengerer FH, Schultz T, Dick HB (2012) Effect of femtosecond laser fragmentation on effective phacoemulsification time in cataract surgery. J Refract Surg 28(12):879-83

33. Price FW, Jr., Price MO (2008) Femtosecond laser shaped penetrating keratoplasty: oneyear results utilizing a top-hat configuration. Am J Ophthalmol 145:210-214.

34. Smith RT, Waring GO, Durrie DS, Stahl JE, Thomas P (2009) Corneal endothelial cell density after femtosecond thin-flap LASIK and PRK for myopia: a contralateral eye study. J Refract Surg 25:1098-1102.

35. Yang $X$, Jiang F, Song Y, Peng C, Sheng S, Li X (2010) Accidental macular injury from prolonged viewing of a plasma flash produced by a femtosecond laser. Ophthalmology 117:972-975.

36. Cain CP, DiCarlo CD, Rockwell BA, Kennedy PK, Noojin GD, Stolarski DJ, Hammer DX, Toth CA, Roach WP (1996) Retinal damage and laser-induced breakdown produced by ultrashortpulse lasers. Graefes Arch Clin Exp Ophthalmol 234 Suppl 1:S28-S37.

37. Cain CP, Toth CA, Noojin GD, Stolarski DJ, Thomas RJ, Rockwell BA (2002) Thresholds for retinal injury from multiple near-infrared ultrashort laser pulses. Health Phys 82:855-862.

38. Roach WP, Rogers ME, Rockwell BA, Boppart SA, Stein CD, Bramlette CM (1994) Ultrashort laser pulse effects in ocular and related media. Aviat Space Environ Med 65:A100-A107.

39. Thomas RJ, Noojin GD, Stolarski DJ, Hall RT, Cain CP, Toth CA, Rockwell BA (2002) A comparative study of retinal effects from continuous wave and femtosecond mode-locked lasers. Lasers Surg Med 31:9-17.

40. Al-Mohtaseb Z, He X, Yesilirmak N, Waren D, Donaldson KE (2017) Comparison of Corneal Endothelial Cell Loss Between Two Femtosecond Laser Platforms and Standard Phacoemulsification. J Refract Surg 33:708-712.

41. Yesilirmak N, Diakonis VF, Sise A, Waren DP, Yoo SH, Donaldson KE (2017) Differences in energy expenditure for conventional and femtosecond-assisted cataract surgery using 2 different phacoemulsification systems. J Cataract Refract Surg 43:16-21.

42. Al-Khateeb G, Shajari M, Vunnava K, Petermann K, Kohnen T (2017) Impact of lens densitometry on phacoemulsification parameters and usage of ultrasound energy in femtosecond laser-assisted lens surgery. Can J Ophthalmol 52:331-337.

FIGURES

Figure 1A: Surgical microscope view of femtosecond laser restricted to capsulotomy creation without lens fragmentation (Group 1).

Figure 1B: Surgical microscope view of femtosecond laser treated cataract demonstrating threeplane chop pattern (Group 2).

Figure 1C: Surgical microscope view of femtosecond laser treated cataract demonstrating 32segment, pie-cut pattern lens fragmentation (Group 3).

Table 1: Patient demographics and surgical parameters in eyes receiving different lens fragmentation patterns during laser-assisted cataract surgery 
Figure 1a

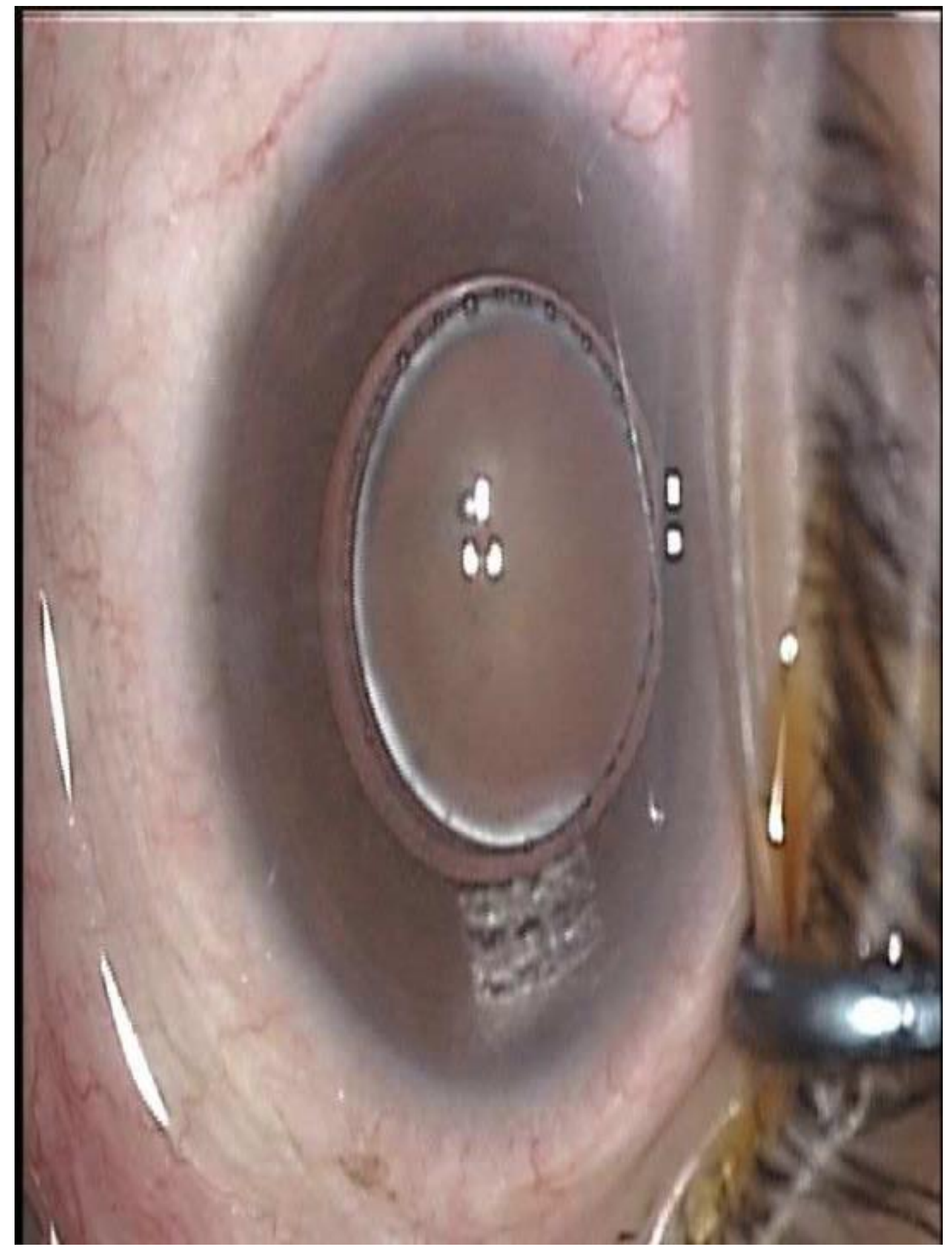


Figure $1 b$

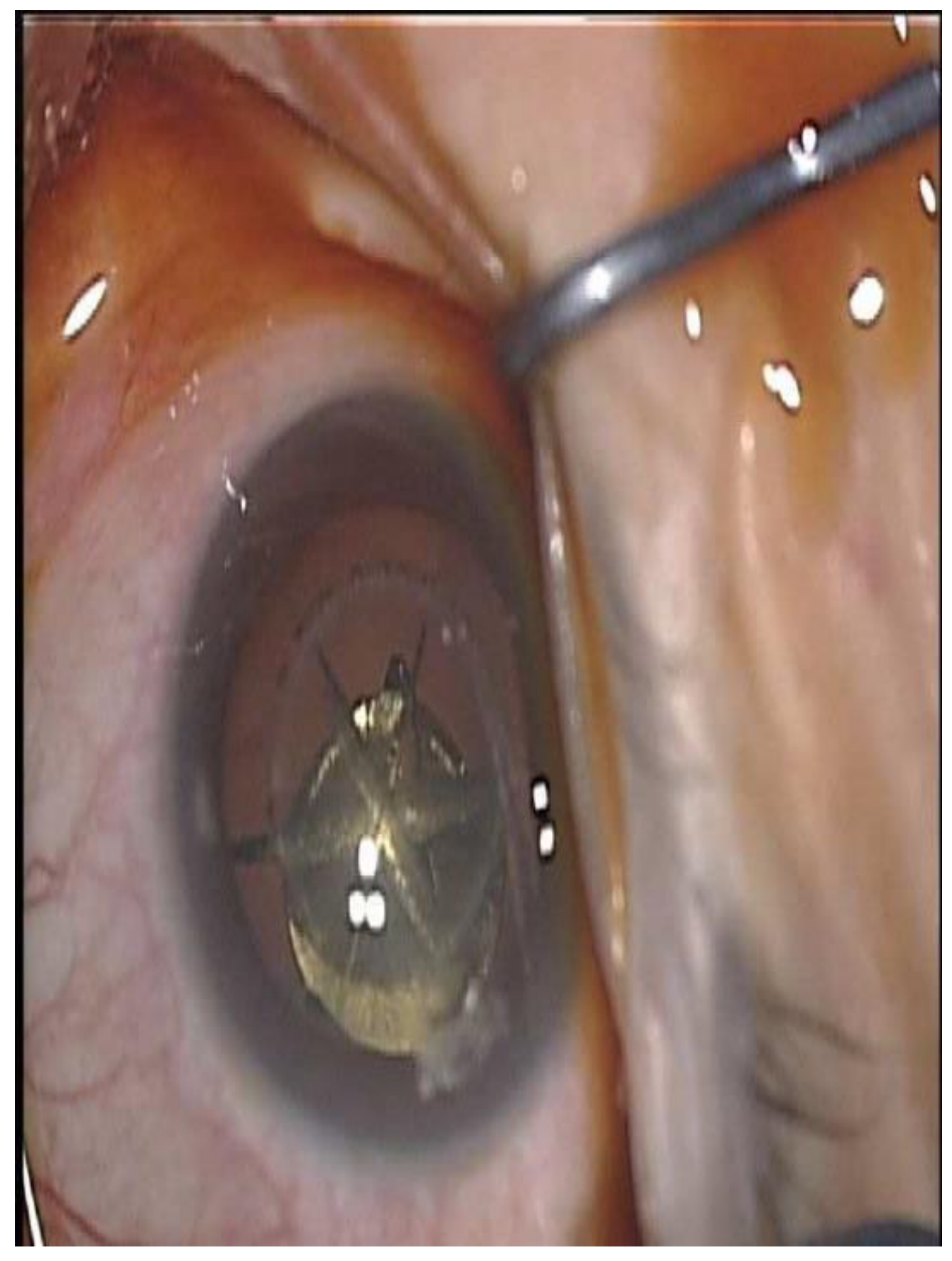


Figure 1c

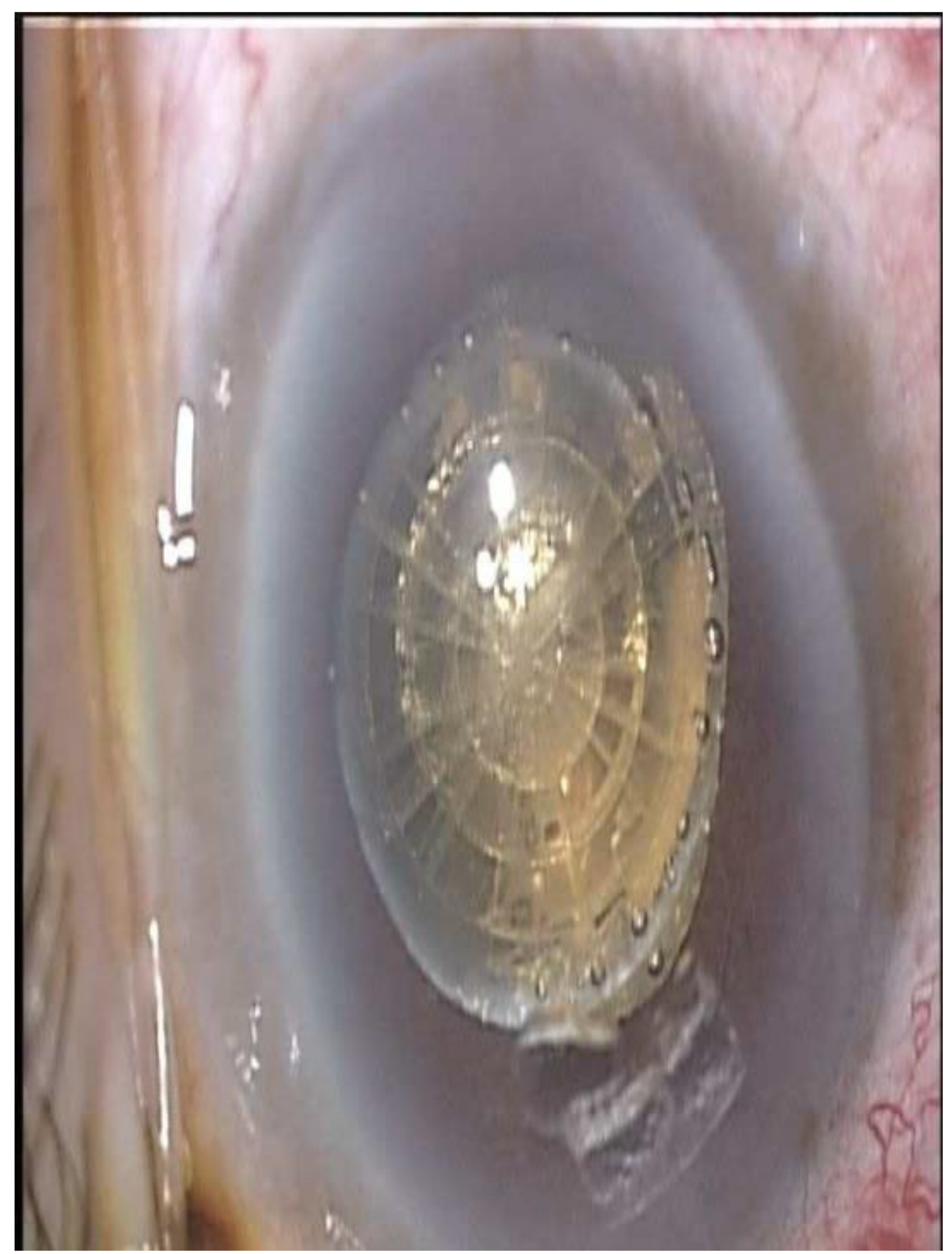


Table 1: Patient demographics and surgical parameters in eyes receiving different lens fragmentation patterns during laser-assisted cataract surgery.

Table 1: Patient demographics and surgical parameters in eyes receiving different lens fragmentation patterns during laser-assisted cataract surgery.

\begin{tabular}{|c|c|c|c|c|}
\hline PARAMETER & $\begin{array}{l}\text { NO LENS } \\
\text { FRAGMENTATION } \\
\text { Mean } \pm \text { SD } \\
\text { (\%) }\end{array}$ & $\begin{array}{l}\text { THREE-PLANE } \\
\text { CHOP } \\
\text { Mean } \pm \text { SD } \\
\text { (\%) }\end{array}$ & $\begin{array}{l}\text { PIE-CUT PATTERN } \\
\text { FRAGMENTATION } \\
\text { Mean } \pm \text { SD } \\
\text { (\%) }\end{array}$ & $\begin{array}{l}\text { P- } \\
\text { VALUE* }\end{array}$ \\
\hline AGE & $70.15 \pm 8.49$ & $67.41 \pm 9.71$ & $66.36 \pm 7.00$ & 0.164 \\
\hline $\begin{array}{l}\text { NS GRADE } \\
\text { GRADE } 0 \\
\text { GRADE } 1 \\
\text { GRADE } 2 \\
\text { GRADE } 3\end{array}$ & $\begin{array}{l}7(20.6 \%) \\
18(52.9 \%) \\
9(26.5 \%) \\
0\end{array}$ & $\begin{array}{l}5(15.2 \%) \\
18(54.5 \%) \\
7(21.2 \%) \\
3(9.1 \%)\end{array}$ & $\begin{array}{l}6(18.2 \%) \\
18(54.5 \%) \\
8(24.2 \%) \\
1(3.0 \%)\end{array}$ & 0.669 \\
\hline DOCK TIME & $\mathrm{N} / \mathrm{A}$ & $145.56 \pm 14.11$ & $184.18 \pm 25.86$ & $<0.001$ \\
\hline ENERGY & $\mathrm{N} / \mathrm{A}$ & $10.00 \pm 0.0$ & $10.00 \pm 0.0$ & N/A \\
\hline PE TIME & $46.15 \pm 23.72$ & $35.60 \pm 18.82$ & $23.19 \pm 17.20$ & $<0.001$ \\
\hline PE POWER & $14.41 \pm 1.88$ & $14.15 \pm 2.51$ & $11.81 \pm 3.71$ & $<0.001$ \\
\hline CDE & $6.55 \pm 3.32$ & $6.64 \pm 5.51$ & $2.85 \pm 2.32$ & $<0.001$ \\
\hline IRRIGATION FLUID & $55.18 \pm 21.53$ & $53.78 \pm 24.96$ & $52.73 \pm 14.84$ & 0.887 \\
\hline OR TIME & $10.09 \pm 1.40$ & $10.53 \pm 2.08$ & $10.30 \pm 1.43$ & 0.619 \\
\hline
\end{tabular}

*Legend: NS: nuclear sclerosis grading; PE: phacoemulsification; CDE: cumulative dissipated energy; OR: operative. 
**Statistical program used SPSS version 17.0. For categorical variables (e.g NS grade, Seal) Chisquare test was used. For comparison of means, One-Way Anova was used. 